\title{
Factors that impact how civil society intermediaries perceive evidence
}

\author{
William L Allen, University of Oxford, william.allen@compas.ox.ac.uk
}

Civil society organisations increasingly mediate the creation and exchange of evidence in their activities with policymakers and practitioners. This paper extends knowledge on evidence in policymaking settings to civil society contexts. As an exploratory and qualitative study, it shows how nine UK-based organisations working on issues including migration and social welfare hold different perceptions of evidence and its usefulness. A range of related factors involving individuals, organisations, sectors, and issue areas emerge as contingent contributors to these variations. As a result, researchers and practitioners seeking to engage with civil society using evidence should consider context-specific values, skills, motivations, and timeliness.

Keywords: civil society; evidence-based research; intermediaries; knowledge exchange

\section{Introduction}

In recent years, the civil society sector has produced, consumed, and commissioned a great deal of 'evidence', and continues to do so. As datasets and tools for accessing them become more widely available, increasingly under the auspices of 'Big' or 'Open' data initiatives, they introduce more potential sources for evidence that takes a myriad of forms including reports, policy briefings, or statistical releases. Here, 'civil society' is conceived as the space lying outside of public states and private businesses, sometimes called the 'third' sector, and can include non-governmental organisations, voluntary organisations, and charities (Bastow, Dunleavy, and Tinkler 2014). They are called 'intermediaries' in the context of this article because they increasingly translate and package research for other end users like policymakers and practitioners (Tseng 2012).

However, given this landscape and digital transformation, do more data and evidence straightforwardly feed into more informed users? Borrowing from the famous aphorism of Chris Anderson (2008), do data and evidence really 'speak for themselves'? Or, do other factors create different perceptions of what evidence is and what it accomplishes? Some scholars have shown how the concept of data is actually value- and values-laden (Graham 2011; Ruppert 2013). Meanwhile, research into public policy reveals how types of evidence and their usages are deeply political: sometimes they serve very different functions than originally intended (Boswell 2009; Brown 2014). But less work turns this critical lens to civil society contexts to consider how these organisations themselves perceive and harness evidence to achieve their aims (Easton-Calabria and Allen 2015).

This article extends thinking on what 'evidence' is in policy spheres and applies it to civil society contexts. Using a qualitative, exploratory research design among a selection of 
UK-based civil society intermediaries including some working on migration and social welfare issues, it addresses two key questions: (1) How do civil society organisations perceive and use research evidence in their activities? (2) What factors at the micro-, meso-, and macro-levels impact on these perceptions and practices? It uses a critical realist approach in order to bring people, politics, and power back into discussions about the role of research in, and on, civil societies. This is in response to recent calls within the field to think about evidence use in ways that are 'socially embedded' (Strassheim and Kettunen 2014), account for different kinds of actors (Boaz and Gough 2014), and acknowledge it as a process that 'demand[s] a combination of different skills and techniques that are time and context specific' (Murdock, Shariff, and Wilding 2013: 428). In total, it argues researchers need a better understanding of civil society intermediaries themselves-their audiences, values, abilities, objectives-in order to understand not only how they use data and evidence, but also for whom and under what circumstances they may do so.

\section{'Evidence' in Public Administration and Policy Studies}

A great deal of knowledge on 'evidence' comes from the field of public policy studies and public administration, where the concept is usually invoked via terms like 'evidence-based policymaking'. Within the UK context, this was a utilitarian approach to research that particularly featured in government policy development under New Labour in the early 2000s. It aimed to make policy more scientific, informed by empirical research, and answerable to the question 'what works?' Until then, received wisdom about how policymaking happens suggested that it was messy, slow, and prone to backtracking through successive administrations. Charles Lindblom, a scholar of public administration, described it as 'muddling through' (Lindblom 1959, 1979). Similarly, Donald Schön described the work of practitioners as existing in 'swampy lowlands' (1983: 42-43) full of messiness and confusion.

In contrast, evidence-based approaches promised to gain the 'high ground' of hard facts, conferring a big picture view of the whole lay of the land (Parsons 2002). Evidence, when rigorously applied to social problems, would enable policymakers to avoid pitfalls and identify which proposed solutions were most likely to actually succeed. In a 2000 address to the Economic and Social Research Council, then-Secretary of State for Education and Employment and former Labour MP David Blunkett explained what kinds of 'evidence' fit the bill:

We're not interested in worthless correlations based on small samples from which it is impossible to draw generalisable conclusions. We welcome studies which combine large-scale, quantitative information on effect sizes which allow us to generalise... (Blunkett 2000)

'Evidence' in this context possesses specific qualities: it is quantitative, systematic, generalisable, and acutely directed at solving problems. Yet, as several scholars have observed, evidence-based policymaking should be more cautiously interpreted as part of a broader modernising project that attempted, imperfectly, to rationalise policy to achieve particular ends (Solesbury 2001; Sanderson 2011). 
But, although there is a great deal of understanding about how evidence is perceived and used in policymaking fields, there is less consensus about how these processes exist in civil society contexts-or even if they hold at all. Whether due to some organisations' small sizes (McCabe 2010) or fewer available resources for studies, this gap is vital to fill: not only are civil society organisations numerous, particularly in the UK, but they also can play a crucial role in linking interests by acting as intermediaries who inform the work of practitioners as well as policymakers (Murdock, Shariff, and Wilding 2013).

\section{Knowledge Exchange: Organisations as Intermediaries for Evidence}

Viewing civil society organisations as 'intermediaries' highlights their importance in relation to evidence. Generally, 'intermediaries' are any actors or organisations that serve as brokers, links, or connections among other peers. They may facilitate, modify, or redirect information passing through them. In policymaking, pressure-groups or think tanks might be intermediaries between legislators and members of the public who share similar viewpoints. Tseng (2012) describes these intermediaries as re-packagers or communicators of academic studies to time- or resource-strapped organisations which otherwise couldn't afford or access them.

These actions, sometimes called 'knowledge exchange' when they occur among researchers, non-academic users, or a combination of both (Kitagawa and Lightowler 2013), are relatively well-studied (Mendoza et al 2013; Oliver et al 2014). In a recent Special Issue of Evidence \& Policy, several researchers and practitioners presented case studies exploring how intermediaries like think tanks (Smith, Kay, and Torres 2013) actually operate in complex situations. This line of work fits within a broader tradition that stretches back to Weiss' (1979) seminal work under the banner of 'research utilization'. Weiss and subsequent scholars such as Levitt (2013) found that the quality of interactions-and eventual use of evidence-is influenced by factors like relevance (including timing or opportunity), legitimacy (credibility and validity of the knowledge itself), and accessibility (clarity, availability of resources). These factors are in turn influenced by users' own perceptions of what counts as 'evidence' (Toner et al 2014) that are shaped by prior opinions, preferences, and interests (Cherney et al 2015).

Usefulness is also impacted by the extent to which the issue area is polarised and contains multiple-sometimes divergent-conceptions of problems and solutions. Boswell (2009) explains that knowledge exchange in issue areas of low polarisation tends to be characterised by a technical focus, dialoguing activities, and 'rational' arguments. Meanwhile, exchanges in issue areas of high polarisation tend to produce strategic actions rather than consensus through rational discussion because there is less agreement about the very terms of the debate. Using research also comes with costs for knowledge producers, intermediaries, and users (Oliver et al 2014). These include time, funding, and attention. All of these factors operate against a backdrop of social relations and structures among participants. Trust, open communication, professional relationships, and shared beliefs about the value of the knowledge use activities themselves help provide stability and facilitate knowledge use (Contandriopoulos et al 2010).

So, what we know from the literature on knowledge exchange in policymaking settings is that a range of micro-, meso-, and macro-level factors-ranging from individual 
perceptions to characteristics of whole issue areas-influence how intermediaries view, use, and transmit evidence (Sebba 2013). As Levitt argues, 'evidence is always contingent on context, sources, perceptions and timing' (2013: 9). Recent work is beginning to show how these contingent factors can be taken from a policymaking context and applied to studies of civil societies. Morton, drawing on an impact assessment of two projects in Scotland that linked researchers with a children's voluntary organisation, emphasises that non-academic end users play important roles in using evidence and generating subsequent impacts: 'research users are not passive recipients of knowledge but...they engage with research from their own perspective' (2015: 50). Meanwhile, Murdock, Shariff, and Wilding observe from a study of knowledge exchange with voluntary sector organisations how the process of knowledge uptake is 'dynamic, reciprocal and non-linear' (2013: 428). These kinds of studies echo the overarching messages of Weiss (1979) and Nutley et al. (2007) in policymaking contexts: knowledge and evidence use should be analysed as a complex, interactive process.

\section{Theoretical Approach: Critical Realism}

To take this forward and apply existing work to civil society contexts, this article uses a critical realist approach. Critical realism can be thought of as a post-positivist way of understanding the world that develops from Karl Popper's (1956) perspective on developing knowledge through criticism of previous knowledge, and Roy Bhaskar's (1975) emphasis on explaining unobservable realities and causes. It is 'critical' because, unlike positivism, it acknowledges that different kinds of knowledge and people who hold them are both imperfect and influenced by their specific contexts: they do not exist in neutral, objective vacuums (Cruickshank 2011). Meanwhile, it is 'realist' because, unlike social constructivism, it argues that an understanding of the underlying causes that drive social phenomena is still accessible by research despite these context-specific features-and that a full analysis should account for them (Brown 2007).

What does a critical realist approach contribute to current understanding of how civil society organisations perceive and use evidence? First, it moves the discussion away from a 'how-to' perspective in search of universalist lessons and towards more nuanced understanding of the underlying factors which contribute towards particular outcomes. And second, critical realism is well-suited for making sense of how specific contexts-whether at individual, organisational, or institutional levels-actually matter for civil society organisations. Playing on the language of some of the evidence-based policymaking literature, critical realism goes beyond 'what works' and asks what works, for whom, and under what circumstances (Pawson et al. 2005). This is potentially more useful for civil society organisations which, like policymaking bodies, must make multiple decisions in the face of imperfect knowledge (Valentini 2010).

\section{Study Context, Data, and Methods}

To answer the research questions and see how factors operating at different levels impact perceptions and practices surrounding evidence, this project used international migration and social welfare as two broad issue areas from which to snowball sample civil society organisations. These topics are highly contentious for the British public, where problems and 
solutions are not well-defined. Instead, they feature numerous trade-offs depending on divergent priorities and values (Threadgold 2009). For example, policies and interventions involving migrants can be influenced by differing conceptions of what should constitute 'appropriate' levels of migration (Migration Observatory 2013). Meanwhile, public representation about poverty in particular tends to lack sophisticated discussion about underlying factors and causes, leading some to characterise it as an 'orphan phenomenon' without clear origins (Chauhan and Foster 2014). These qualities make them particularly good issue areas in which to look for variations in how evidence is used and perceived. They also feature activities from a range of charities, non-governmental organisations, and community groups which can be collected under the broad category of civil society (Bastow, Dunleavy, and Tinkler 2014).

Inclusion criteria were kept intentionally broad to capture a range of migration- and social-welfare oriented organisations of different sizes that engage in policy, campaigning, volunteering, or advocacy. In reality, most of the organisations engaged in a mixture of these activities. In total, nine organisations whose activities are primarily based in the UK agreed to participate in the study. Three organisations exclusively focused on migration issues, while three others featured social welfare projects or aims that also included migrant groups. Since it was exploratory and qualitative in nature, the project also secured participation from three larger organisations outside of these issue areas that tend to coordinate or communicate activity among other voluntary and civil society organisations. This helped broaden the findings and enable them to speak to other issues. To give a sense of these organisations' variety, Table 1 lists some that agreed to participate in the study and be named, along with an excerpt from their public mission statements as of August 2014.

From these nine organisations, 12 mid- to senior-level staffmembers agreed to participate in semi-structured interviews. Interviewees had roles involving research, public policy outreach, management, or communications. As part of the process of gaining ethical clearance from the University of Oxford, the author offered participants the opportunity to contribute on an anonymous basis before each interview, and then revisited this permission afterwards. This step was important because the questions might have revealed time- or context-sensitive practices, such as commissioning new reports or studies. Therefore, some identifying titles and names have been changed to protect confidentiality when requested.

The research also uses corpus linguistic methods to analyse the published language of most of these organisations. One organisation was omitted from the linguistic analysis because its materials were largely journalistic pieces while another had agreed to participate after the data collection had occurred. Corpus methods are a broad set of quantitative and qualitative techniques that analyse a body of assembled texts for patterns or variation in usage. Public-facing outputs can serve to establish and communicate organisations' positions or missions. They also provide a window into how organisations make sense of their issue areas to present particular viewpoints. By detecting patterns of language around mentions of the key terms 'data' and 'evidence', corpus linguistic techniques reveal insights not immediately apparent from a selective reading of a limited number of documents, while also preserving access to qualitative insights gained from closer examination of individual items (McEnery and Hardie 2011). 
Table 1. Example Organisations Agreeing to Participate in the Study

\begin{tabular}{|c|c|c|}
\hline Organisation & Mission or Statement of Purpose & Headquarters \\
\hline Eaves & $\begin{array}{l}\text { Lead the way in exposing and addressing the } \\
\text { overlapping issues of domestic abuse, sexual } \\
\text { violence, and exploitation of women in the UK. }\end{array}$ & London \\
\hline $\begin{array}{l}\text { Joseph } \\
\text { Rowntree } \\
\text { Foundation } \\
\text { (JRF) }\end{array}$ & $\begin{array}{l}\text { Want lasting change for people and places in } \\
\text { poverty, communities where everyone can thrive } \\
\text { and a more equal society. Now and for future } \\
\text { generations. }\end{array}$ & York \\
\hline $\begin{array}{l}\text { Migrant Rights } \\
\text { Network } \\
\text { (MRN) }\end{array}$ & $\begin{array}{l}\text { Working and campaigning in support of migrants } \\
\text { in the UK. Our work brings together migrant } \\
\text { activists and support organizations, think tanks, } \\
\text { academics, faith groups and public sector } \\
\text { representatives to advocate for a rights-based } \\
\text { approach towards migration in the UK. }\end{array}$ & London \\
\hline $\begin{array}{l}\text { Scottish } \\
\text { Refugee } \\
\text { Council }\end{array}$ & $\begin{array}{l}\text { A Scotland in which all people seeking refugee } \\
\text { protection are welcome. It is a place where } \\
\text { women, children and men are protected, find } \\
\text { safety and support, have their human rights and } \\
\text { dignity respected and are able to achieve their full } \\
\text { potential. }\end{array}$ & Glasgow \\
\hline Renaisi & $\begin{array}{l}\text { Dedicated to making improvements to } \\
\text { disadvantaged communities, putting local people } \\
\text { at the centre of positive change through our } \\
\text { extensive experience delivering neighbourhood- } \\
\text { based regeneration programmes, local economic } \\
\text { development initiatives and employment services. }\end{array}$ & London \\
\hline
\end{tabular}

The dataset included, as far as possible, all research reports, news items, policy briefings, and results from public consultations that they had published online between 2007 and mid-2014. A research assistant retrieved and charted these documents, converted them to text files, and removed images, captions, and bibliographies where present. During the data collection, the assistant and author regularly checked a sample of documents for consistency in formatting and quality. This procedure resulted in a corpus of 2,704 items containing 9,487,330 words, which was uploaded to the software package Sketch Engine for organisation and analysis.

This period is especially interesting because it includes several important shifts impacting both British civil society as well as the issue areas of migration and social welfare. These included two successive British governments under different parties from 2007-2010 and 2010-onwards; several controversial migration policy changes like the 2007 UK Borders Act and 2014 Immigration Bill that prompted interventions by civil society organisations; and the 2010 announcement of the UK government's 'Big Society' initiative that aimed to support community-based organisations and local citizens in providing services previously run by public bodies (Jacobs 2014). Since the research questions ask how evidence is perceived and used by civil society organisations, it makes sense to choose a period when evidence might be used either in public debate or to inform new strategic directions.

Since critical realist approaches direct attention towards underlying factors that may contribute to observed differences, it is preferable to combine methods that access multiple layers of a phenomenon (Pratt 1995). The following two results sections explore how 'data' and 'evidence' feature in organisations' public outputs and staffmembers' perceptions. 


\section{Three Emergent Conceptions of 'Evidence' in UK Civil Society}

Themes that emerged from the interviews suggest at least three ways civil society organisations think about and act upon the concept of 'evidence': it is a way of improving knowledge, supporting existing viewpoints, or demonstrating impact or authority to external stakeholders.

First, if the aim of the evidence-gathering activity was to identify important but previously undetected aspects of a key issue, then it was seen as a crucial resource for providing guidance for future action. This was also the case where evidence might be generated outside of formal research, such as through practical experiences:

Seeing what works, by finding out what works on the ground and what doesn't work...[to] be able to advise people properly on policies and things like that based on solid, robust research (Programme Manager)

To frontline practitioners or people that are service managers in their local authority, evidence-based is much more 'has somebody else done it before?' To them, evidence is often some sort of proof of concept (Director)

...For us, [evidence] is something that we try and do fairly systematically (Research Manager)

Second, interviewees also used 'evidence' in a sense that supports or illustrates pre-existing viewpoints held by an organisation. Evidence can highlight the importance of an issue as well as generate new ideas. Here, processes of linking activities to organisational missions or values-such as advocating for particular worldviews or policy outcomes-are particularly visible:

I think there is a tendency...to fall into that field of 'we already know that this is an issue and let's do some research and write up a report to show that it is (Head of Policy and Communications)

One participant even candidly characterised some kinds of evidence, particularly when leading up to a key media or policy event, as being a case of 'dirty research', something that involved less stringent methods or reviewing in order to make deadlines and 'get some coverage'. Although this was a minority characterisation-most of the participants coming from academic backgrounds agreed that rigour and systematic enquiry were vital-it does illustrate a spectrum of evidence 'quality' as described by previous studies about knowledge exchange (Levitt 2013).

Finally, civil society organisations also talked about evidence in terms of showing authority and impact to external funders or partners. This might reflect conscious reflection on the part of staffmembers to present organisational activities in advantageous ways, either to prove some kind of measurable change or to establish a degree of expertise about a given issue: 
The Holy Grail of the stuff is can you evidence the impact that you've had on your beneficiaries? And that's really difficult to do. (Senior Research Officer)

I think if you use the word 'evidence' it will give some sort of authority to do with that word that there isn't just in 'data' (Policy and Research Manager)

This last point is well-illustrated by looking at the corpus data. What kinds of words modify 'data' and 'evidence' in these organisations' publications? Table 2 shows the top 20 modifiers of each term, ranked by overall frequency. Modifiers are words that describe the key terms, and are usually but not always adjectives. As highlighted in blue, words used with 'data' tend to centre on sources and types: CENSUS and ADMINISTRATIVE for sources, and QUANTITATIVE, QUALITATIVE, LONGITUDINAL, and STATISTICAL for types. Meanwhile, the top 20 modifiers of 'evidence' include more references to subjective qualities or strengths as highlighted in orange. Adjectives like LITTLE, CLEAR, STRONG, ROBUST, and LIMITED illustrate this point. This suggests that these organisations modify mentions of 'evidence' with words that point to trustworthiness and heightened (or in some cases lessened) strength.

Table 2. Top 20 Modifiers of 'Data' and 'Evidence' in the Civil Society Corpus

\begin{tabular}{|cc|cc|}
\hline Modifiers of DATA & Frequency & Modifiers of EVIDENCE & Frequency \\
\hline survey & 135 & little & 211 \\
\hline census & 128 & research & 145 \\
\hline qualitative & 105 & anecdotal & 84 \\
\hline quantitative & 87 & available & 77 \\
\hline available & 78 & clear & 73 \\
\hline administrative & 59 & strong & 66 \\
\hline local & 48 & limited & 64 \\
\hline more & 41 & further & 55 \\
\hline recent & 40 & empirical & 51 \\
\hline statistical & 39 & recent & 50 \\
\hline interview & 38 & more & 46 \\
\hline migration & 35 & other & 44 \\
\hline longitudinal & 33 & robust & 39 \\
\hline such & 33 & international & 35 \\
\hline reliable & 32 & good & 32 \\
\hline national & 32 & study & 32 \\
\hline other & 32 & case & 31 \\
\hline new & 31 & statistical & 29 \\
\hline detailed & 30 & qualitative & 29 \\
\hline late & 30 & new & 29 \\
\hline & & & \\
\hline
\end{tabular}

\section{Factors Contributing to Variations in Perceptions and Practices}

What accounts for these different perceptions of 'evidence'? The interviews suggested four sets factors. The first involves audiences: different circles view the usefulness of evidence differently depending on their intended users or beneficiaries. Policymakers whose 
conclusions could potentially affect an entire population have different expectations of evidence compared to service providers directly engaging with clients on a daily basis:

$[Y]$ ou have to remember that service provision...is about people who have vulnerabilities or are victims of crime or victims of prejudice. And it's about meeting those needs, it's not about the bigger population all the time (Policy and Research Manager)

They [Members of Parliament] like things bound up to look professional and they like them to be rigorous and they like them to be independent. (Policy Director)

The second set of factors involves available skills such as numeracy or confidence in accessing datasets. Participants expressed doubts about their users' need and capacity to either access and understand evidence, particularly when it came in numerical forms.

[A local service manager's] skillset isn't massively numerate...They'll work out how to take a budget and do as many things as they can with it, but they're not thinking about data in that sort of way at all (Director)

There is the fear of either too many charts for example, it's not just too many numbers all rammed in the text but too many charts that can be overwhelming (Senior Commissioning Editor)

These factors are important to consider given the increasing availability of information through 'Open' and 'Big' data initiatives (Easton-Calabria and Allen 2015). As the 'volume, velocity, and variety' (Laney 2001) of available data increases, so do the potential benefits and drawbacks of using these data to inform civil society activities (Ross 2013). As several interviewees explained, available skills and decision-making abilities are crucial to ensure that these initiatives are indeed useful for civil society:

People will be able to get their hands on all kinds of things...[Big Data] is something that they should be aware of and something that if we use it in the right way people can benefit from obviously. (Programme Manager)

I actually think [if] you could have all the data open, it wouldn't mean necessarily that the data would be used. I think it's good to have open data and you'd have to think through what people need to actually use the data. So, the two conversations, [are] linked. I think actually not many people can use the open data that's available. You do have to have specialist skills... (Senior Research Officer)

A third set of factors involves the environmental demands of the civil society sector and specific issue areas. Many of these organisations engage with fast-moving, contentious, 
or emotive topics, not all of which are either clearly defined or immediately solvable. Furthermore, many of the participating organisations rely on external funding from foundations to keep running. These kinds of environmental demands-of timeliness, of public opinion, of what 'counts' as convincing evidence by funders-also influence perceptions:

So sometimes [evidence-based research] is [sic] things that are done quickly and fast just to keep the momentum of an issue (Head of Policy and Communications)

People find numbers more convincing. So if they are making a funding application, they feel more desperate to have some numbers in it than to have qualitative research findings in it as a basis of funding them. (Policy and Research Manager)

Finally, a fourth set of factors revolves around these organisations' values and missions. Organisations prioritise activities which match and enhance their existing values and practices. Ascribing value to certain kinds of evidence is one such activity. As mentioned earlier, intended audiences play a role in influencing these perceptions:

Part of our theory of change is that political negativity towards [migrants] and legislation impacts on them. Part of the creation of that is because that is desirable amongst the public and there is a lack of knowledge about...migration generally. So part of it is to try to increase public understanding so that people have better attitudes and behaviours (Head of Policy and Communications)

[O]ur business is to be politically neutral to provide strategic support and information for those organisations to then go and do their job with it...we see ourselves as providing some more objective information that [local authorities] would otherwise have (Policy and Research Manager)

If an organisation values neutrality, 'rigour', or independence, this may lead them to prefer quantitative data as a kind of 'evidence' that should feature in their work. As an earlier participant explained, numbers are perceived to be convincing.

These findings are echoed in the textual data. What do data and evidence do or accomplish in civil society organisations' public outputs? Looking for verbs or actions associated with these concepts when they are the main subject of a sentence can help answer this question. Table 3 shows the top 20 verbs that meet these criteria. Within the corpus, actions associated with 'evidence' and 'data' tend to either relate to supporting a given claim or revealing particular insights. As indicated by the words highlighted in blue, verbs associated with DATA when it is the subject of a sentence tend to present information. Meanwhile, the verbs used with 'evidence' express more of a particular stance, as illustrated by words like SUGGEST (over five times more frequently used with 'evidence' rather than 
'data'), SUPPORT (three times more frequent), CONFIRM, and HIGHLIGHT. However, some of these verbs indicating a degree of selection are also present with mentions of DATA, such as DEMONSTRATE and SUPPORT.

Table 3. Top 20 Verbs Appearing with 'Data' and 'Evidence' in the Civil Society Corpus

\begin{tabular}{|cc|cc|}
\hline Verbs \& DATA as Subject & Frequency & Verbs \& EVIDENCE as Subject & Frequency \\
\hline be & 489 & suggest & 393 \\
\hline show & 103 & be & 331 \\
\hline suggest & 64 & show & 107 \\
\hline have & 53 & indicate & 56 \\
\hline relate & 32 & have & 52 \\
\hline do & 31 & support & 49 \\
\hline provide & 29 & demonstrate & 35 \\
\hline set & 25 & do & 30 \\
\hline indicate & 22 & present & 29 \\
\hline regard & 17 & regard & 28 \\
\hline support & 14 & relate & 25 \\
\hline include & 14 & highlight & 16 \\
\hline use & 14 & review & 15 \\
\hline reveal & 13 & emerge & 14 \\
\hline present & 13 & confirm & 12 \\
\hline demonstrate & 11 & point & 12 \\
\hline become & 11 & concern & 11 \\
\hline cover & 10 & provide & 10 \\
\hline share & 9 & appear & 9 \\
\hline allow & 8 & exist & 9 \\
\hline
\end{tabular}

\section{Perceptions of Evidence in Civil Society: A Model of Multi-level Factors}

How do civil society organisations working on migration and social welfare, among other topics, perceive 'evidence'? It is a way of improving knowledge, supporting existing viewpoints, and demonstrating impact or authority to external stakeholders. The interview data suggest these uses are influenced by factors like audiences, available skills, political and funding contexts, and organisational missions.

Table 4 organises these factors into a model of multiple levels, organised by scale (primarily involving individuals, organisations, sectors, or issue areas) and by whether they are more related to operations or to guiding values-although it is understood that this division is rarely clear-cut. It generalises the insights and reflections of interviewees into broader concepts, which are identified in italics. But separating out these concepts does not imply that they are unrelated: instead, by organising them in this particular way, this model tries to show their interrelationships, draw out the significance of the findings for other issue areas, and identify possible avenues for further investigation.

Skills are specific abilities (programming, statistical knowledge, volunteer management) that individual team members bring to their organisations. Staff also bring personal motivations to their work-whether these are worldviews, ideals, or notions of satisfaction. These factors impact perceptions at the micro-level by shaping individuals' confidence or familiarity with evidence, as well as their willingness to engage with it. 
Table 4. Multi-level Factors Impacting Civil Society Perceptions of Evidence

\begin{tabular}{|c|ccc|}
\hline \multicolumn{2}{|c}{ Scale } & Operations & Values \\
\hline \multirow{2}{*}{ Macro-Level } & Issue Areas & $\begin{array}{c}\text { Target Group } \\
\text { Demographics }\end{array}$ & $\begin{array}{c}\text { Polarisation, } \\
\text { Public Opinion }\end{array}$ \\
\hline \multirow{2}{*}{ Meso-Level } & Sectors & Stakeholders & $\begin{array}{c}\text { Norms, } \\
\text { Conventions }\end{array}$ \\
\cline { 2 - 4 } & Organisations & Strategies & Missions \\
\hline Micro-Level & Individuals & Skills & Motivations \\
\hline
\end{tabular}

Meanwhile, civil society organisations build and revise operational strategies that guide decisions about where to spend limited resources like time and funds. These are informed by more abstract missions that might be expressed as 'theories of change', or simply through vision statements. Civil society organisations are also located within an entire sector that interacts with shared stakeholders like policymakers, private businesses, and public bodies. As a result, the sector also has certain norms and conventions about what counts as 'good practice'. These meso-level factors shape what is seen as 'effective' and 'high-quality' evidence-or whether it is valued at all.

Finally, at the macro-level, characteristics of a given issue area also influence perceptions of evidence. Target group demographics can raise or lower the visibility of certain populations: in the case of migration, demographic shifts could make immigration issues more important in geographic areas that have experienced high levels of recent migration. Polarisation and public opinion are also factors that can create incentives for organisations to use evidence in ways that advantage their existing campaigning and advocacy work.

In total, the model suggests that the interaction of micro-, meso-, and macro-level factors create a range of perceptions of, as well as possibilities, for civil society organisations' engagement with evidence. They also help explain why this range exists: the specific mixtures of individual, organisational, sectoral, and issue area dynamics generate context-specific responses. Sometimes, individuals with valuable skills take centre stage, while in other cases key stakeholders demand certain kinds of evidence. And, where the issues at stake are polarising or fast-moving, options like long-term projects are just not feasible or desirable no matter the promised outcomes.

Looking at this multi-level model through a critical realist lens reveals how people, politics, and power run through these dynamics. Unlike technocratic, evidence-based policymaking approaches that are concerned with 'what works', critical realism is more concerned with identifying what works for whom and under what circumstances. People are key in this model, whether as staffmembers with skills, motivations, confidence, or anxieties; audiences with particular expectations and interests shaped by prior experiences; or as members of the public whose opinions influence what is considered 'acceptable' or 
'necessary' action. A full analysis of the role of evidence in civil society must acknowledge and account for the range of socio-cultural factors specific to people occupying each level.

But as people interact with one another across these levels, politics of various forms emerge. At the micro- and meso-levels, who gets access to skills training that can put evidence, possibly of a quantitative nature, within reach-and which organisations have the available resources and strategic will to provide such opportunities to their staff? More generally, as voluntary and charitable organisations are expected to do more with fewer resources, this raises questions about how the civil society sector operates as a whole: does it promote collaboration and coordination among its members, or does it foster even greater competition? Meanwhile, as prevailing opinion and policy developments shape an issue area, stakeholders can respond by demanding certain kinds of evidence that are seen to be politically relevant.

This model also shows how power plays its role in shaping perceptions about what 'counts' as evidence in the first place. The study results suggest that answering this question depends on a keen understanding of the context: who is involved, what organisational objectives or missions are at stake, how polarised is the issue area? Power relations, as Brown (2014) observes in the case of evidence use in education policymaking, can determine which kinds of evidence are prioritised over others-or which kinds are deemed as inferior or unacceptable. These kinds of hierarchies, Freshwater and Rolfe (2001) argue using the case of nursing, are more broadly reinforced by dividing research from practice. In much the same way, perceptions about evidence in civil society contexts also depend on whom or what exerts power in a given situation.

\section{Opportunities and Implications for Research Practice}

Several opportunities and implications for future research practice emerge from this study. First, researchers hoping to introduce evidence in civil society contexts need to have a fuller understanding of the values, motivations, and strategies which guide these organisations' decision-making. Study of public documents showed how terms like 'evidence' often convey certain stances in addition to producing new knowledge. However, this only reveals part of the story about the roles of evidence in achieving an organisation's mission. Why it would value or use evidence at all could be related either to how its members perceive its usefulness or worthiness in helping achieve its mission.

Second, understanding the opportunities and limitations associated with 'Open' and 'Big' data initiatives, particularly from official sources like the UK government, is an important objective for these organisations. As shown in the earlier section, some interviewees emphasised that the changing nature and means of accessing data was an emerging concern. These initiatives have the potential to make more information available to organisations that need it most, but it presents additional problems related to the skillsets of researchers who are accessing them.

Third, greater awareness of the needs, practices, and motivating factors facing academics and civil society or voluntary organisations can improve the ways researchers design and execute their work. Throughout the interviews, there was a shared perception that researchers did not always consider either the time constraints upon organisations or how both parties' objectives could be mutually achieved in practice: 
I would say you need to be a bit more fleet of foot and you need to understand the sort of pressures, both in terms of resources and time on NGOs. Academic papers are not our primary objective within doing this work. They are a helpful add on and add to the credibility of what we are doing but it's not the main focus. (Head of Policy and Communications)

Certainly for NGOs where you are, as soon as you put something out it is almost over and they are looking for the next thing and the next thing. So, you know, it is hard to produce quickly enough. (Policy Director)

Finally, and following on from the third lesson, the findings imply that consciously engaging with partners from the beginning of a project is crucial. Mutually considering and outlining the envisioned goals of exchange nearer the outset-even if they eventually change-provides enough time to allow all involved parties to become familiar with the specific mixes of factors, needs, and skills that are present. These combinations will be different in each interaction as conditions change:

...[I]t is important to think about what you want to get out of it at the end at the beginning and to think more about the dissemination and the impact of the dissemination when you are actually designing it. (Programme Manager)

It would be about building a relationship, something should come out of that research, which also supports the organisation in terms of providing service or of giving them credit in their involvement in that research. (Lead Researcher)

\section{Conclusion}

By qualitatively examining the perceptions and practices surrounding the use of 'evidence' in a selection of British civil society organisations, this study sought to take what is already known about evidence use in policymaking and knowledge exchange contexts and apply it to civil society contexts. It found that 'evidence' was perceived in at least three ways: as a way of identifying gaps in knowledge; as a way of supporting already-held positions; and as a way of demonstrating authority or impact. These perceptions emerge through the interaction and mixture of a range of factors involving individuals, organisations, sectors, and issue areas. People, politics, and power also influence how these interactions play out in different contexts.

Given these multiple factors, researchers should consider some key messages as they produce evidence and engage with civil society organisations. First, properly estimate the role of values and organisational objectives in decision-making. Second, address new and different skillsets demanded by emerging 'Big' and 'Open' datasets. Third, appreciate all parties' motivations, needs, and capacities which might constrain as well as enable certain kinds of activities. And fourth, since all of these factors are contingent and time-specific to a certain extent, include time to develop shared goals and intended outcomes from the beginning. 
There are several important limitations of this study to bear in mind. As an exploratory, qualitative study using non-representative sampling, its findings are not generalisable to the whole of British civil society. Instead, the research design intended to seek out possible variations in how evidence was perceived within a more delimited set of issues, and then uncover a range of reasons for the observed variety. Furthermore, speaking only with mid- to senior-level staff reveals how certain parts of an organisation work-and from particular perspectives. Finally, quantitative corpus linguistic techniques like frequency analysis do not necessarily account for either external circumstances that may have influenced how the text was produced, or nuances of argument that cannot be explicitly counted (McEnery and Hardie 2011). But, due to its links with critical realist theory as well as being informed by existing work on knowledge exchange, this study does contribute new knowledge about how evidence is perceived in civil society contexts and puts forward multiple levels of factors that potentially influence these perceptions.

Where next? The critical realist imperative of attending to context-specific factors suggests that more research needs to be done that looks at how civil society organisations in other issue areas as well as geographic contexts actually use evidence. Nutley et al. (2010) provide a helpful overview of comparative analysis of evidence in policymaking across several European cases. Similarly-styled work in civil society settings might reveal how the different factors identified in this study play out in different locations. Also, the issue of skills development at individual and organisational levels raises critical ethical questions about who is being left out of public debate that increasingly depends on opaque, statisticsdriven data and evidence (Easton-Calabria and Allen 2015). And, as researchers are increasingly required to show how their work has impact beyond the academy, possibly within civil societies, there is a pressing need to identify those elements that are key to users' successful engagement with research (Morton 2015).

In their recent editorial for Evidence \& Policy, Boaz and Gough observe how current thinking about the role of evidence in decision-making-both in policy and practical settings-is 'gradually expanding to make room for a wider range of actors' (2014: 312). Civil society organisations are increasingly part of these processes, mediating how evidence is translated, transmitted, and sometimes transformed. If researchers and practitioners are to have their desired effects through use of evidence in the realms of civil societies, then they need to be conscious of the multiple factors that bear upon this process-and perhaps most importantly, understand that the process of engagement itself may take different appearances depending on who is involved and under what circumstances it occurs. 


\section{Works Cited}

Anderson, C, 2008, The end of theory, Wired Magazine, 16, 1

Bastow, S, Dunleavy, P, Tinkler, J, 2014 The impact of the social sciences: how academics and their research make a aifference, London: Sage

Bhaskar, R, 1975, A Realist Theory of Science, London: Verso

Blunkett, D, 2000, Influence or irrelevance: Can social science improve government? Research Intelligence, 72, 12-21

Boaz, A, Gough, D, 2014, Towards a systems perspective on evidence-based policy, Evidence \& Policy: A Journal of Research, Debate and Practice, 10, 311-312

Boswell, C, 2009, The political uses of expert knowledge: Immigration policy and social research, Cambridge: Cambridge University Press

Brown, C, 2007, Situating critical realism, Millennium - Journal of International Studies, 35, 409-416

Brown, C, 2014, The policy agora: How power inequalities affect the interaction between researchers and policy makers, Evidence \& Policy: A Journal of Research, Debate and Practice, 10, 421-438

Chauhan, A, Foster, J, 2014, Representations of Poverty in British Newspapers: A Case of "Othering" the Threat? Journal of Community \& Applied Social Psychology, 24, 390-405.

Cherney, A, Head, B, Povey, J, Ferguson, M, Boreham, P, 2015, Use of academic social research by public officials: Exploring preferences and constraints that impact on research use. Evidence \& Policy: A Journal of Research, Debate and Practice, 11, 169-188

Contandriopoulos, D, Lemire, M, Denis, J L, Tremblay, E, 2010, Knowledge exchange processes in organizations and policy arenas: A narrative systematic review of the literature. Milbank $Q, 88,444-483$

Cruickshank, J, 2011, Positioning positivism, critical realism and social constructionism in the health sciences: A philosophical orientation, Nursing Inquiry, 19, 71-82

Easton-Calabria, E, Allen, W L, 2015, Developing ethical approaches to data and civil society: from availability to accessibility. Innovation: The European Journal of Social Science Research, 28, 52-62.

Freshwater, D, Rolfe, G, 2001, Critical reflexivity: A politically and ethically engaged research method for nursing. Nursing Times Research, 6, 526-537.

Graham, M, 2011, Time machines and virtual portals: The spatialities of the digital divide, Progress in Development Studies, 11, 211-227

Jacobs, K, 2014, The Allure of the "Big Society": Conveying Authority in an Era of Uncertainty. Housing, Theory and Society, 32, 25-38.

Kitagawa, F, Lightowler, C, 2013, Knowledge exchange: A comparison of policies, strategies, and funding incentives in English and Scottish higher education, Research Evaluation, 22, 1-14 
Laney, D, 2001, 3D data management: Controlling data volume, velocity, and variety, http://blogs.gartner.com/doug-laney/files/2012/01/ad949-3D-Data-Management-ControllingData-Volume-Velocity-and-Variety.pdf

Levitt, R, 2013, The challenges of evidence, Provocation Paper for the Alliance for Useful Evidence, NESTA. NESTA, London.

Lindblom, C E, 1959, The science of "muddling through", Public Administration Review, 19, 79-88

Lindblom, C E, 1979, Still muddling, not through yet, Public Administration Review, 39, 517526

McCabe, A, 2010, Below the radar in a big society? Reflections on community engagement, empowerment and social action in a changing policy context. Birmingham: Third Sector Research Centre, University of Birmingham

McEnery, T, Hardie, A, 2011, Corpus linguistics: method, theory and practice. Cambridge: Cambridge University Press

Mendoza, E R H, Perz, S G, Souza da Silva, S, Brown, I F, Pinheiro, P S, 2014, Revisiting the knowledge exchange train: Scaling up dialogue and partnering for participatory regional planning, Journal of Environmental Planning and Management, 57, 384-402

Migration Observatory, 2013, Evidence and values - The UK migration debate 2011-2013. Oxford: Centre on Migration, Policy, and Society, University of Oxford

Morton, S, 2015, Creating research impact: the roles of research users in interactive research mobilisation. Evidence \& Policy: A Journal of Research, Debate and Practice, 11, 35-55.

Murdock, A, Shariff, R, Wilding, K, 2013, Knowledge exchange between academia and the third sector, Evidence \& Policy: A Journal of Research, Debate and Practice, 9, 419-430

Nutley, S, Walter, I, Davies, HTO, 2007. Using Evidence: How Research Can Inform Public Services. Bristol: Policy Press.

Nutley, S, Morton, S, Jung, T, Boaz, A, 2010, Evidence and policy in six European countries: diverse approaches and common challenges. Evidence \& Policy: A Journal of Research, Debate and Practice, 6, 131-144.

Oliver, K, Innvar, S, Lorenc, T, Woodman, J, Thomas, J, 2014, A systematic review of barriers to and facilitators of the use of evidence by policymakers, BMC Health Services Research, 14

Parsons, W, 2002, From muddling through to muddling up - Evidence based policy making and the modernisation of British government, Public Policy and Administration, 17, 43-60

Pawson, R, Greenhalgh, T, Harvey, G, Walshe, K, 2005, Realist review: a new method of systematic review designed for complex policy interventions. Journal of Health Services Research \& Policy, 10, 21-34.

Popper, K, 1956, Realism and the Aim of Science. Routledge: London 
Pratt, A C, 1995, Putting critical realism to work: the practical implications for geographical research, Progress in Human Geography, 19, 61-74

Ross, D, 2013, Big data and social organisations: A state of the art review, Nominet Trust Ruppert, E, 2013, Rethinking empirical social sciences, Dialogues in Human Geography, 3, 268-273

Sanderson, I, 2011, Evidence-based policy or policy-based evidence? Reflections on Scottish experience, Evidence \& Policy: A Journal of Research, Debate and Practice, 7, 5976

Schön, D, 1983, The Reflective Practitioner, New York: Basic Books

Sebba, J, 2013, An exploratory review of the role of research mediators in social science. Evidence \& Policy: A Journal of Research, Debate and Practice, 9, 391-408

Smith, K E, Kay, L, Torres, J, 2013, Think tanks as research mediators? Case studies from public health, Evidence \& Policy: A Journal of Research, Debate and Practice, 9, 371-390

Solesbury, W, 2001, Evidence based policy: Whence it came and where it's going, ESRC UK Centre for Evidence Based Policy and Practice Working Paper Series, London: Queen Mary University of London.

Strassheim, H, Kettunen, $\mathrm{P}, 2014$, When does evidence-based policy turn into policy-based evidence? Configurations, contexts and mechanisms, Evidence \& Policy: A Journal of Research, Debate and Practice, 10, 259-277.

Threadgold, T, 2009, The Media and Migration in the United Kingdom, 1999 to 2009, Public Opinion, Media Coverage, and Migration, Bellagio, Italy: Migration Policy Institute

Toner, P, Lloyd, C, Thom, B, MacGregor, S, Godfrey, C, Herring, R, Tchilingirian, J, 2014, Perceptions on the role of evidence: an English alcohol policy case study, Evidence \& Policy: A Journal of Research Debate and Practice, 10, 93-112

Tseng, V, 2012, The uses of research in policy and practice, Social Policy Report, 26, 3-16 Valentini, C, 2010, On objective knowledge in social sciences and humanities: Karl Popper and beyond, Max Weber Programme Working Paper Series, Florence, Italy: European University Institute

Weiss, $\mathrm{C} \mathrm{H}, 1979$, The many meanings of research utilization, Public Administration Review, 39, 426-431. 